\title{
Corrosion and Wear Properties of Cu-TiC Composites Produced by Hot Pressing Technique
}

\author{
Mehmet Akkaş${ }^{1}$, Serkan Islak ${ }^{1 *}$, Cihan Özorak ${ }^{2}$ \\ ${ }^{1}$ Kastamonu University, Faculty of Engineering and Architecture, Mechanical Engineering, Kastamonu, Turkey \\ ${ }^{2}$ Kastamonu University, Faculty of Engineering and Architecture, Metallurgical and Materials Engineering, \\ Kastamonu, Turkey \\ *serkan@kastamonu.edu.tr
}

Received: 20 September 2018

Accepted: 15 October 2018

DOI: $10.18466 /$ cbayarfbe.461839

\begin{abstract}
$\mathrm{Cu}-x \operatorname{TiC}(\mathrm{x}=0,1,5,10$ and $15 \mathrm{wt} . \%)$ composites were prepared by hot pressing (HP) technique. The microstructure, corrosion and wear features of $\mathrm{Cu}$ matrix composites (CMCs) were investigated. The wear surfaces and microstructure of the CMCs were analyzed using SEM-EDS. Phases of samples were identified by means of XRD. Hardness measurements of the composites were made using a microhardness device. Hardness tests showed that the hardness tends to increase with increasing TiC amount. Wear properties of the CMCs were determined using ball-on-disc method. Significant decreases in wear rates were observed in composites reinforced with $\mathrm{TiC}$. The corrosion properties of the composites were characterized by potentiostatic polarization test. Corrosion results showed that the corrosion resistance of the composites decreased with the increase of $\mathrm{TiC}$ content in $\mathrm{Cu}$. Among the composites, $\mathrm{Cu}-1 \% \mathrm{TiC}$ has the best corrosion resistance.
\end{abstract}

Keywords: $\mathrm{Cu} / \mathrm{TiC}$ composite, hot press, wear, corrosion.

\section{Introduction}

Nowadays, copper matrix composites (CMCs) have been produced by addition of oxides, carbide and boride particles to copper matrix due to the copper's excellent thermal and electrical conductivity, superb corrosion and oxidation resistance exhibits poor wear resistance $[1,2]$. CMCs have desirable mechanical properties and electrical conductivity properties at a reasonable level compared to pure copper. These composites are candidate materials especially in areas where good wear resistance is required $[3,4]$.

The quality of the bonding on the matrix and reinforcement interface is important in terms of wear properties of the composite in $\mathrm{Cu}$ matrix particulate reinforced composites. If the bond between the reinforcement and the matrix is weak, the wear rate increases. In this case, reinforcements cause three-body abrasion during wear [5].

When literature has been searched, generally $\mathrm{Al}_{2} \mathrm{O}_{3}, \mathrm{SiC}$, $\mathrm{TiB}_{2}$ and WC particles have been used as reinforcement particles in CMSs. Zhu et al [6] investigated wear characteristics of $\mathrm{Cu} / \mathrm{SiC}_{\mathrm{p}}$ produced by pressurized infiltration method. In the study a very high percentage of (61 vol.\%) SiC was added to copper. Result showed that as the wear load and sliding distance increases, the wear losses increase. At the same time, when the grain size of reinforcements increased, the wear rates increased. Fathy et al [7] investigated wear behavior of
CMCs reinforced 2.5, 7.5 and 12.5 wt. $\% \mathrm{Al}_{2} \mathrm{O}_{3}$. It has been reported that with increasing of $\mathrm{Al}_{2} \mathrm{O}_{3}$ ratio, the wear rate increased, and the electrical conductivity decreased.

In this study, wear and corrosion properties of CMCs reinforced with $0-15$ wt.\% $\mathrm{TiC}$ were investigated. TiC was selected as reinforced particles because it have high hardness $(\sim 30.3 \mathrm{GPa})$, high elasticity modulus, low density, high electrical conductivity $\left(30 \times 10^{6} / \Omega \mathrm{cm}\right)$ and stable properties at high temperature [8-11]. Besides, it is resistant to wear because $\mathrm{TiC}$ have a high melting temperature and low thermal expansion coefficient [12].

\section{Materials and Methods}

$\mathrm{Cu}$ and $\mathrm{TiC}$ powders having a purity of $99.9 \%$ were used as raw materials. The particle size of $\mathrm{Cu}$ was $20 \mu \mathrm{m}$, while $\mathrm{TiC}$ was $10 \mu \mathrm{m} .1,5,10$ and 15 were selected as (wt.\%). The CMCs were prepared in the hot-pressing machine in an argon gas atmosphere. The production parameters were $700{ }^{\circ} \mathrm{C}$ sintering temperature, $4 \mathrm{~min}$ sintering time and $50 \mathrm{MPa}$ pressure. The densities were determined according to Archimedes' principle [13]. Wear tests were carried out with a CSM brand wear device according to ASTM G133 standard. The tests were performed with $10 \mathrm{~N}$ load, $5 \mathrm{~cm} / \mathrm{s}$ wear speed and $300 \mathrm{~m}$ wear distance. Wear properties were evaluated sliding a WC steel $3 \mathrm{~mm}$ diameter ball against the specimens. Surface of wear were examined by using scanning electron microscope. 
Hardness's were measured using a Shimadzu HVM-2.

For corrosion experiments, the specimens were sanded and cleaned in the ultrasonic bath. Measurements were made using $\quad 3000$ Potentiostat/Galvanostat/ZRA corrosion system. The experiments were performed after the specimens were allowed to stand at room temperature in a $3.5 \mathrm{wt} . \% \mathrm{NaCl}$ $(\mathrm{pH} 3)$ for 1 hour. In order to detect corrosion rates, anodic/cathodic Tafel zones were used. Polarization resistance values were calculated from the linear regions.

\section{Results and Discussion}

The optical photographs of the CMSs are given in Figure 1. Pores are present at least in the unadulterated $\mathrm{Cu}$ sample (Figure 1a). The amount of pores in the $\mathrm{Cu}$ sample is less than that in the reinforced TiC sample (Figure 1b). From the SEM-MAP analysis in Figure 2, it is clear that the $\mathrm{TiC}$ grains are relatively homogeneously distributed in the $\mathrm{Cu}$ matrix. The homogeneous distribution of the grains in the matrix affects the mechanical and physical properties positively.
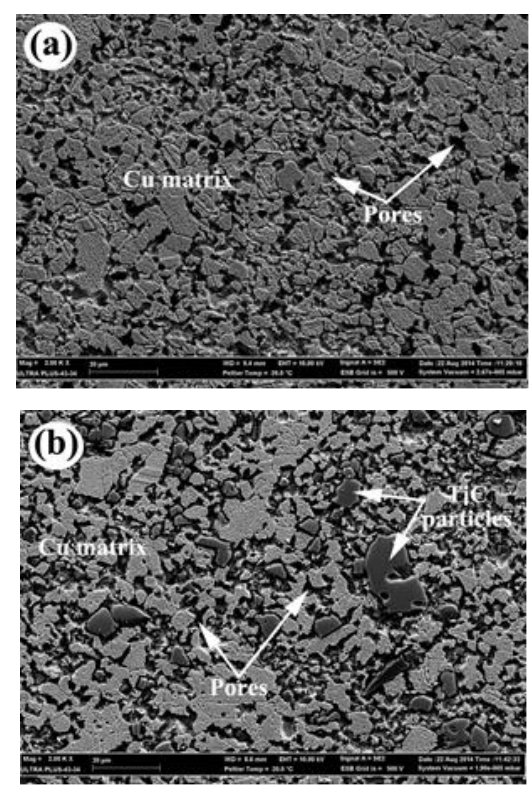

Figure 1. SEM images of (a) $\mathrm{Cu}$ and (b) $\mathrm{Cu}-5$ wt.\% TiC.

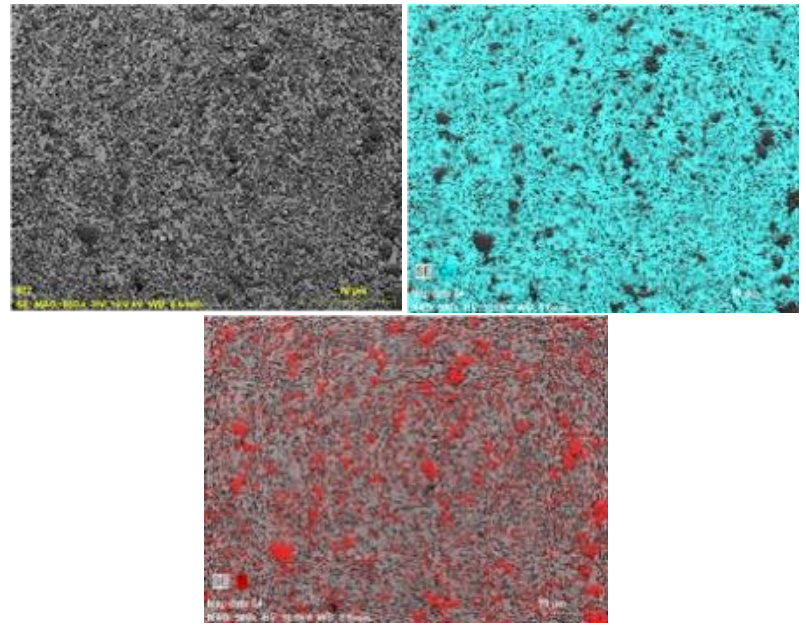

Figure 2. MAP analysis for $\mathrm{Cu}-5$ wt. \% TiC composite.

$\mathrm{XRD}$ graph of the CMCs is given in Figure 3. It is clear that two phases, $\mathrm{Cu}$ and $\mathrm{TiC}$, are present in the structure. The phases in the CMCs could be identified as TiC with diffraction peaks at about $2 \theta=35.9^{\circ}, 41.7^{\circ}$ and $60.6^{\circ}$ and $\mathrm{Cu}$ with diffraction peak at about $2 \theta=43.3^{\circ}, 50.2^{\circ}$ and $74.0^{\circ}$. There was no phase formation between $\mathrm{Cu}$ and TiC. This can be explained by the insufficient energy supply.

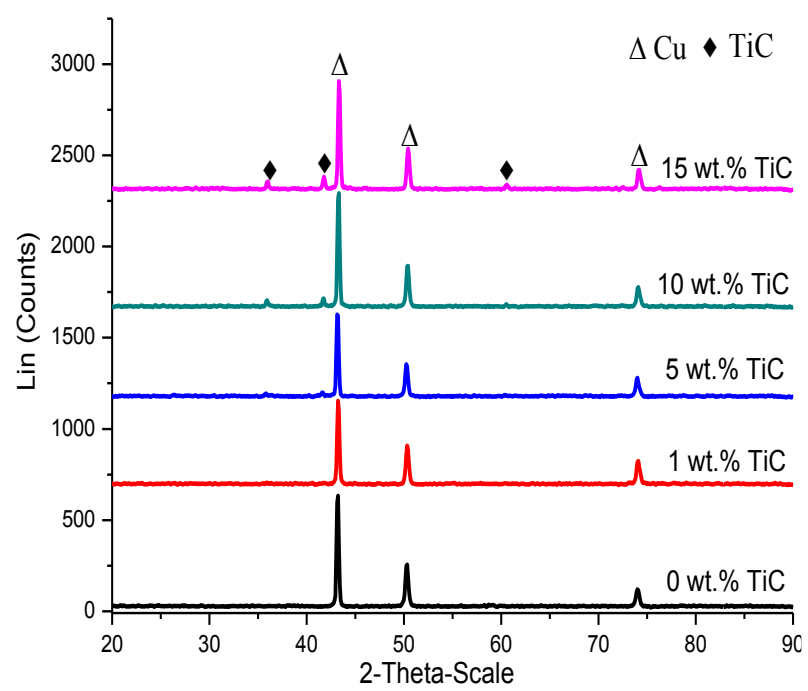

Figure 3. XRD graph of CMCs.

The hardness and relative density of the CMCs are summarized in Table 1. As the TiC addition amount increased, the hardness increased, while the relative densities decreased. Since sintering of carbides with very high melting temperatures is very difficult, they are negatively affecting the sinter ability of the composites when they are reinforcements. This negative effect leads to an increase in pore content and hence a decrease in the relative density [14]. TiC brings about dispersion strengthening, which causes an increase in the hardness of the $\mathrm{CMCs}$. 
Table 1. Relative density and hardness properties of composites.

\begin{tabular}{|c|c|c|}
\hline $\begin{array}{c}\text { TiC content } \\
\text { (wt. \%) }\end{array}$ & $\begin{array}{c}\text { Relative density } \\
(\boldsymbol{\%})\end{array}$ & $\begin{array}{c}\text { Hardness } \\
\left(\mathbf{H V}_{\mathbf{0 . 1}}\right)\end{array}$ \\
\hline 0 & 98.6 & 47.5 \\
\hline 1 & 98.1 & 58.6 \\
\hline 5 & 93.3 & 76.3 \\
\hline 10 & 84.3 & 83.4 \\
\hline 15 & 78.8 & 87.8 \\
\hline
\end{tabular}

$\mathrm{COF}$ and wear rates of the composites are given in the graph in Figure 4. According to graph, while a significant reduction in the wear rate of samples with increase of $\mathrm{TiC}$ occurs, $\mathrm{COF}$ is in decline again. While the coefficient of friction of copper is $\sim 0.745$, the COF of $\mathrm{Cu}-15$ wt. $\% \mathrm{TiC}$ composite is $\sim 0.346$. The wear rate of composites obtained with $0 \%, 1 \%, 5 \%, 10 \%$ and $15 \% \mathrm{TiC}$ addition were $\sim 9.59 \times 10^{-3} \mathrm{~mm}^{3}$.(N.m) $)^{-1}, \sim 4.57 \times 10^{-3} \mathrm{~mm}^{3}$.(N.m $)^{-1}$, $\sim 3.08 \times 10^{-3} \mathrm{~mm}^{3}$. (N.m) $)^{-1}, \sim 4.58 \times 10^{-4} \mathrm{~mm}^{3}$.(N.m) $)^{-1}$ and $\sim 1.41 \times 10^{-4} \mathrm{~mm}^{3}$.(N.m) $)^{-1}$. Wear resistance of $\mathrm{Cu}-15$ wt. $\%$ $\mathrm{TiC}$ composite in comparison to the non-reinforced sample increased approximately 1.5 times.

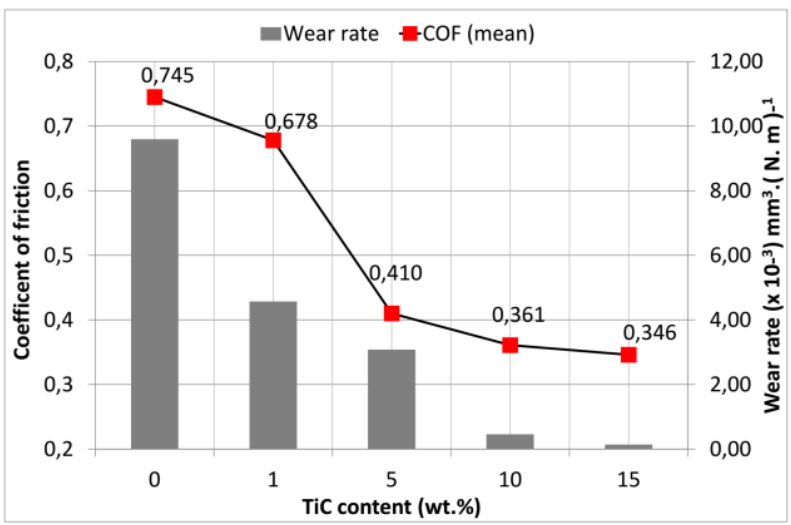

Figure 4. Wear rate and COF depending on TiC content

Figure 5 presents the wear surface of the $\mathrm{Cu}$ matrix. On the wear surface, it is evident that deep grooves, which composed of shear dimples, which indicate that they are the places where the wear debris form. The EDS analysis shows that the oxide is formed on the surface after the wear tests (Figure 5). This oxide film has a lubricating action to reduce the friction coefficient [15]. Besides, the $\mathrm{W}$ element found in the EDS analysis came from the counter object (WC ball).

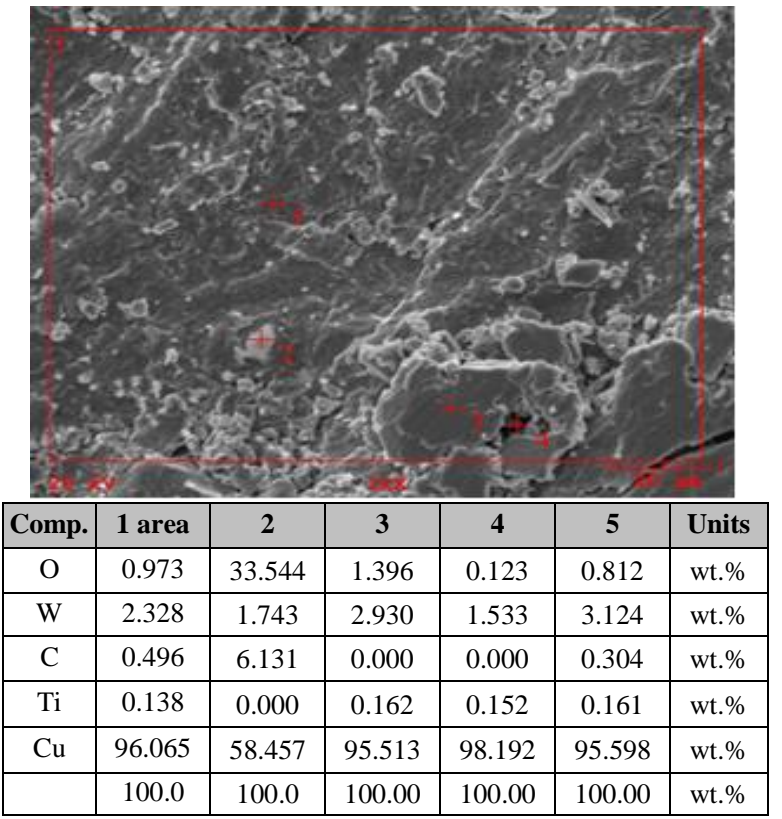

Figure 5. SEM-EDS analysis of the wear surface of unreinforced $\mathrm{Cu}$.

SEM-EDS analysis of wear surface of $\mathrm{Cu}-\mathrm{xTiC}(\mathrm{x}=5$ wt. \% and 15 wt.\%) composites are given in Figure 6. On the worn surface of $\mathrm{Cu}$-TiC composites relatively smaller hollows and wear particles are observed. Hollows and wear particles on the worn surface of $15 \% \mathrm{TiC}$ reinforced copper matrix composite is the smallest (Figure 6b). This is because of the effect of increasing the strength of carbides and the lubricant effect of oxide film. It is observed that abrasive effects on this sample surface are fairly few and oxidations are available in places. Similar to the unreinforced sample, $\mathrm{W}$ element was also detected on the worn surfaces of the $\mathrm{Cu}$-TiC samples.

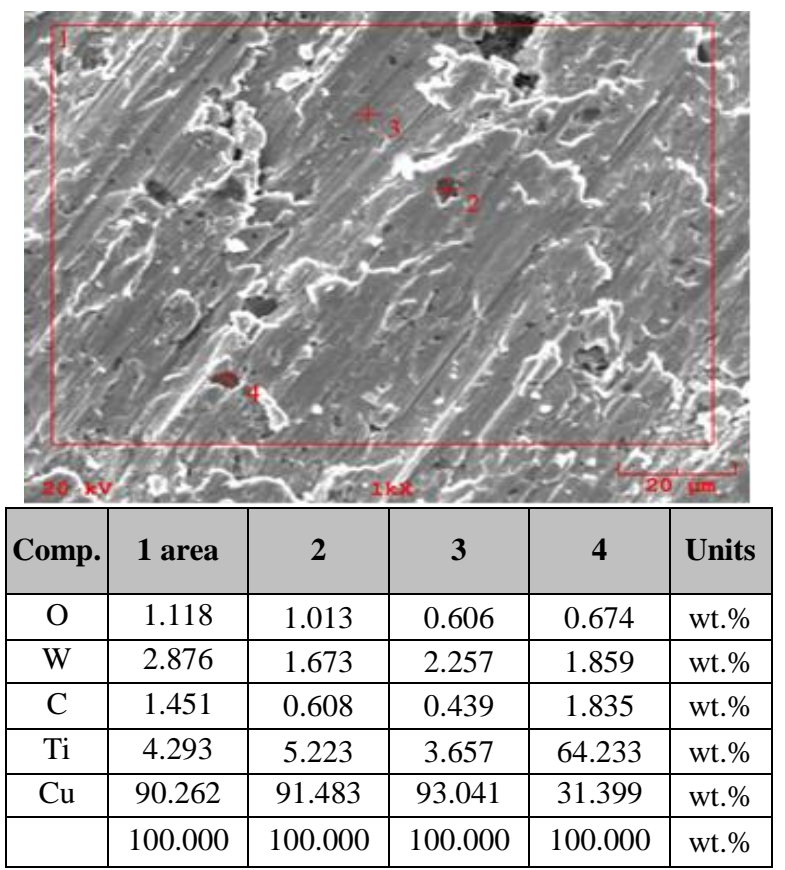

(a) 


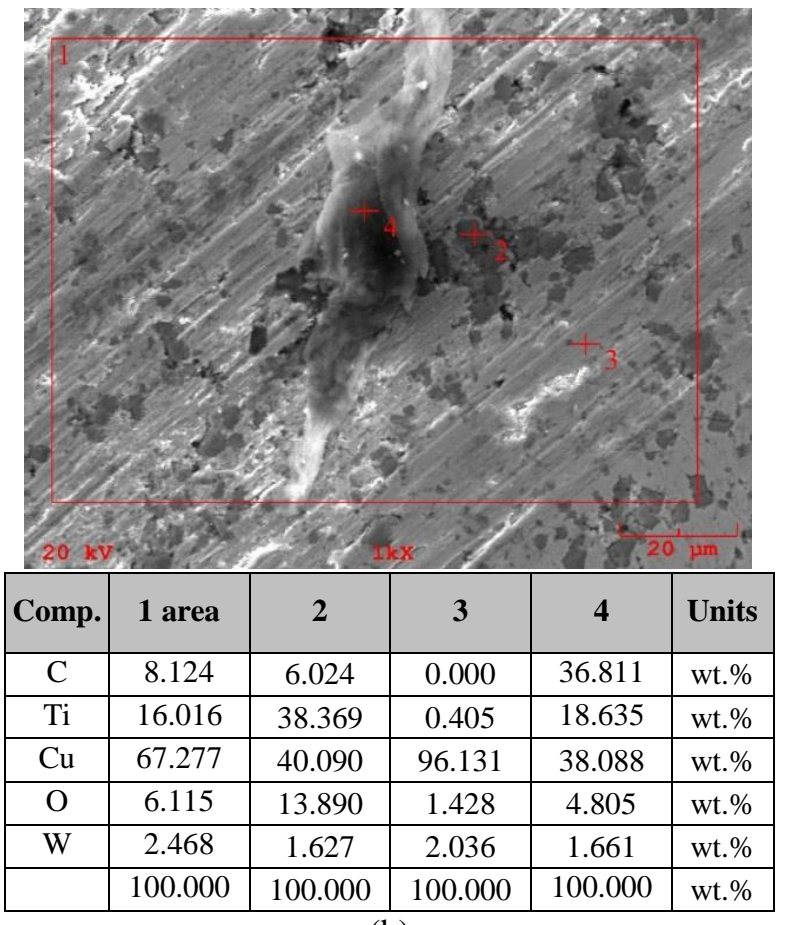

(b)

Figure 6. SEM-EDS analysis of the wear surface of composites: (a) $\mathrm{Cu}-5 \% \mathrm{TiC}$ and (b) $\mathrm{Cu}-15 \% \mathrm{TiC}$.
The potentiodynamic polarization curves of CMCs determined in $3.5 \% \mathrm{NaCl}$ solution are shown in Figure 7. All curves exhibit active passive behavior. The results of the corrosion measurements are summarized in Table 2. Among the samples, the largest corrosion potential has unreinforced copper sample $(-210 \mathrm{mV})$. The lowest corrosion potential among the other samples was measured as $-242 \mathrm{mV}$ for $\mathrm{Cu}-15 \% \mathrm{TiC}$. Among the measured corrosion current values, the smallest value belongs to $\mathrm{Cu}$ sample $\left(6,0 \mu \mathrm{Acm}^{-2}\right)$. In corrosion science, the general approach to corrosion is that low corrosion current and high corrosion potential means low corrosion rate or high corrosion resistance $[16,17]$. According to this approach, it is the $\mathrm{Cu}$ sample which is the most resistant to corrosion between the samples and the $\mathrm{Cu}$ $1 \% \mathrm{TiC}$ composite among the composites. Corrosion rate and corrosion resistance values in Table 2 also support this approach. As the amount of $\mathrm{TiC}$ increased, the resistance of the composite to corrosion decreased. The presence of the $\mathrm{TiC}$ particle in the $\mathrm{Cu}$ matrix caused a second passivation peak to occur. In addition, with the increase in the amount of $\mathrm{TiC}$, the amount of porosity increases. Pores reduce corrosion resistance. Porous areas play a role in facilitating corrosion. The corrosion area expands by increasing the pore quantity [18-20].

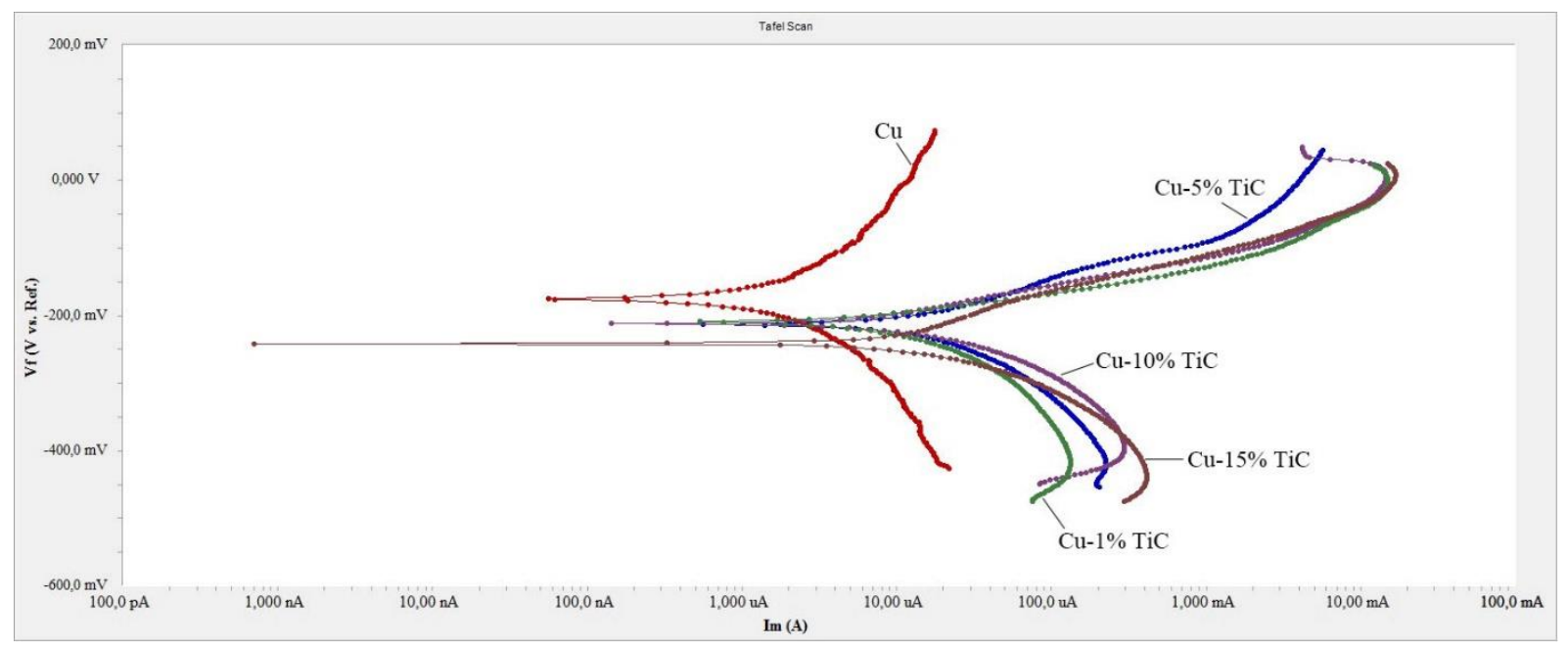

Figure 7. Potentiodynamic polarization curves of CMCs.

Table 2. Electrochemical results of CMCs.

\begin{tabular}{|l|c|c|c|c|c|c|}
\hline Materials & $\mathrm{E}_{\mathrm{cor}}(\mathrm{mV})$ & $\mathrm{I}_{\mathrm{cor}}\left(\mu \mathrm{Acm}{ }^{-2}\right)$ & $\beta_{\mathrm{a}}(\mathrm{mV})$ & $\beta_{\mathrm{c}}(\mathrm{mV})$ & $\begin{array}{c}\text { Corrosion rate } \\
(\mathrm{mpy})\end{array}$ & $\begin{array}{c}\text { Corrosion resistance } \\
\left(\mathrm{k} \Omega . \mathrm{cm}^{2}\right)\end{array}$ \\
\hline $\mathrm{Cu}$ & -210 & 6,0 & 34,5 & 69,6 & 2,724 & 1,669 \\
\hline $\mathrm{Cu}-1 \% \mathrm{TiC}$ & -212 & 6,7 & 50,5 & 49,9 & 3,031 & 1,632 \\
\hline $\mathrm{Cu}-5 \% \mathrm{TiC}$ & -213 & 8,0 & 70,2 & 50,8 & 3,611 & 1,608 \\
\hline $\mathrm{Cu}-10 \% \mathrm{TiC}$ & -215 & 32,0 & 155,1 & 255,3 & 3,794 & 1,308 \\
\hline $\mathrm{Cu}-15 \% \mathrm{TiC}$ & -242 & 43,7 & 163,5 & 358,5 & 19,82 & 1,116 \\
\hline
\end{tabular}




\section{Conclusions}

1. SEM images showed that titanium carbide particulates distributed comparatively uniformly in the copper matrix.

2. By increasing the amount of $\mathrm{TiC}$, relative densities have decreased, and hardness's have also increased.

3. Wear testing of the samples was performed using ball-on-disk method. With addition of TiC, wear rates and coefficient of friction decreased. So samples have become more resistant to abrasion.

4. The presence of $\mathrm{TiC}$ particles in the $\mathrm{Cu}$ matrix caused the corrosion resistance to decrease. The best corrosion resistance among the composites was determined in the $\mathrm{Cu}-1 \mathrm{wt}$ \% $\mathrm{TiC}$ composite.

\section{Acknowledgments}

The authors are grateful to the Scientific Research Projects Unit of Kastamonu University for contributing the KUBAP-01/2012-15 project.

\section{References}

1. Lu, J, Shu, S, Qiu, F, Wang, Y, Jiang, Q, Compression properties and abrasive wear behavior of high volume fraction $\mathrm{TiC}_{\mathrm{x}}-\mathrm{TiB}_{2} / \mathrm{Cu}$ composites fabricated by combustion synthesis and hot press consolidation, Materials \& Design. 2012, 40, 157-162.

2. Eslami, M, Golestani-fard, F, Saghafian, H, Robin, A, Study on tribological behavior of electrodeposited $\mathrm{Cu}-\mathrm{Si}_{3} \mathrm{~N}_{4}$ composite coatings, Materials \& Design. 2014, 58, 557-569.

3. Selvakumar, N, Vettivel, S.C, Thermal, electrical and wear behavior of sintered $\mathrm{Cu}-\mathrm{W}$ nanocomposite. Materials \& Design. 2013, 46, 16-25.

4. Vettivel, S.C, Selvakumar, N, Leema, N, Lenin, A.H, Electrica resistivity, wear map and modelling of extruded tungsten reinforced copper composite, Materials \& Design. 2014, 56, 791 806.

5. Çelikyürek, İ, Körpe, N.Ö, Ölçer, T, Gürler, R, Microstructure, Properties and Wear Behaviors of $\left(\mathrm{Ni}_{3} \mathrm{Al}\right)_{\mathrm{p}}$ Reinforced Cu Matrix Composites, Journal of Materials Science \& Technology. 2011, 27(10) 937-943.

6. Zhang, L. He, X.B, Qu, X.H, Duan, B.H, Lu, X, Qin, M.L, Dry sliding wear properties of high volume fraction $\mathrm{SiC}_{\mathrm{p}} / \mathrm{Cu}$ composites produced by pressureless infiltration, Wear, 2008, 265(11-12), 1848-1856.

7. Fathy, A, Shehata, F, Abdelhameed, M, Elmahdy, M, Compressive and wear resistance of nanometric alumina reinforced copper matrix composites, Materials \& Design. 2012, 36, 100-107.

8. Kaftelen, H, Ünlü, N, Göller, G, Öveçoğlu, M.L, Henein, H, Comparative processing-structure-property studies of $\mathrm{Al}-\mathrm{Cu}$ matrix composites reinforced with TiC particulates, Composites Part A: Applied Science and Manufacturing. 2011, 42, 812-824.

9. Kim, I.Y, Choi, B.J, Kim, Y.J, Lee, Y.Z, Friction and wear behavior of titanium matrix (TiB+TiC) composites, Wear. 2011, 271, 1962-1965.
10. Cheng, L, Xie, Z, Liu, G, Spark plasma sintering of TiC-based composites toughened by submicron $\mathrm{SiC}$ particles, Ceramics International, 2013, 39(5), 5077-5082.

11. Song, G.M, Wu, Y, Li, Q, Elevated temperature strength and thermal shock behavior of hot-pressed carbon fiber reinforced TiC composites, Journal of the European Ceramic Society. 2002, 22(4), 559-566.

12. Nemati, N, Khosroshahi, R, Emamy, M, Zolriasatein, A Investigation of microstructure, hardness and wear properties of Al-4.5 wt. \% Cu-TiC nanocomposites produced by mechanical milling, Materials \& Design. 2011, 32, 3718-3729.

13. ASTM B311-08, Standard test method for density of powder metallurgy (PM) materials. ASTM; 2008.

14. Rahimian, M, Ehsani, N, Parvin, N, Baharvandi, H.R, The effect of particle size, sintering temperature and sintering time on the properties of $\mathrm{Al}-\mathrm{Al}_{2} \mathrm{O}_{3}$ composites, made by powder metallurgy, Journal of Materials Processing Technology. 2009, 209, 53875393.

15. Kumar, G.B.V, Rao, C.S.P, Selvaraj, N, Mechanical and Tribological Behavior of Particulate Reinforced Aluminum Metal Matrix Composites - a review. Journal of Minerals \& Materials Characterization \& Engineering, 2011, 10(1), 59-91.

16. Sun, J, Fu, Q.G, Guo, L.P, Liu, Y, Huo, C.X, Li, H.J, Effect of filler on the oxidation protective ability of $\mathrm{MoSi}_{2}$ coating for Mo substrate by halide activated pack cementation. Materials \& Design. 2016, 92, 602-609.

17. Bakhsheshi-Rad, H.R, Hamzah, E, Ismail, A.F, Daroonparvar, M, Yajid, M.A.M, Medraj, M, Preparation and characterization of NiCrAlY/nano-YSZ/PCL composite coatings obtained by combination of atmospheric plasma spraying and dip coating on $\mathrm{Mg}-\mathrm{Ca}$ alloy, Journal of Alloys and Compounds. 2016, 658, 440452 ,

18. Kim, Y.J, Jang, J.W, Lee, D.W, Yi, S, Porosity effects of a Febased amorphous/nanocrystals coating prepared by a commercial high velocity oxy-fuel process on cavitation erosion behaviors, Metals and Materials International. 2015, 21, 673-677.

19. Li, Y.H, Rao, G.B, Rong, L.J, Li, Y.Y, Ke, W, Effect of pores on corrosion characteristics of porous NiTi alloy in simulated body fluid. Materials Science and Engineering: A. 2003, 363, 356-359.

20. Xie, F, He, X, Cao, S, Mei, M, Qu, X, Influence of pore characteristics on microstructure, mechanical properties and corrosion resistance of selective laser sintered porous Ti-Mo alloys for biomedical applications. Electrochimica Acta. 2013, 105, 121129. 